\title{
Photoluminescence of the first examples of metal-organic frameworks with two novel tetrazolatephenyl acetic acid derivatives: an experimental and theoretical study $\dagger$
}

\author{
Antonio J. Calahorro, ${ }^{a}$ Piero Macchi, ${ }^{\text {bb }}$ Alfonso Salinas-Castillo, ${ }^{c}$ \\ Eider San Sebastián, ${ }^{d}$ José M. Seco ${ }^{d}$ and Antonio Rodríguez-Diéguez ${ }^{\star a}$
}

Received 30th March 2014,

Accepted 22nd September 2014

\section{Introduction}

The metal-organic framework materials currently represent an area of enormous interest owing not only to the need for developing new functional materials but also for elucidating their topologies and their potential applications. ${ }^{1}$ Recently, the design and study of Zn-based MOFs have evolved enormously ${ }^{2}$ due to their interesting structures and in particular their potential applications in areas such as luminescence, ${ }^{3}$ gas adsorption, ${ }^{4}$ sensing, and optical storage. ${ }^{5}$ These materials are commonly prepared through a bottom-up approach using solvothermal methods, connecting ions with the appropriate bridging ligands. Still, there is a great interest in the design of new bridging ligands that will allow the preparation of novel MOFs. Over the last years, we and others have described different metal coordination polymers based on tetrazolate with interesting topologies synthesized by in situ Demko-Sharpless cycloaddition reactions of organonitriles and sodium azide. ${ }^{6}$ Moreover, we have shown the use of hydrothermal syntheses to generate in situ new ligands and construct novel three-dimensional coordination polymers. ${ }^{7}$

\footnotetext{
${ }^{a}$ Departamento de Química Inorgánica, Universidad de Granada, Avda Fuentenueva s/n, 18071, Granada, Spain. E-mail: antonio5@ugr.es

${ }^{b}$ Department of Chemistry and Biochemistry, University of Bern, Freiestrasse 3, CH3012, Bern, Switzerland. E-mail: piero.macchi@dcb.unibe.ch

${ }^{c}$ Departamento de Quimica Analitica, Universidad de Granada, 18071, Granada, Spain

${ }^{d}$ Departamento de Química Aplicada, Facultad de Químicas de San Sebastián, Universidad del País Vasco/Euskal Herriko Unibertsitatea, Paseo Manuel de Lardizabal 3, 20018, San Sebastián, Spain

$\dagger$ Electronic supplementary information (ESI) available.
}

Following our previous studies, we have designed, by hydrothermal routes, two new multidentate bridging anionic ligands which are derivatives of tetrazol-phenyl-acetic acid ( $\mathrm{H}_{2}$ tzbaa), 3-tetrazolatephenyl acetic and 4-tetrazolatephenyl acetic linkers (Scheme I), which contain one carboxylate group and one tetrazolate ring with a methylene-benzene group in the middle of the spacer. Thanks to its extended aromaticity and to the presence of poly-heterosubstituted penta- and hexa-atomic rings, $\mathrm{H}_{2}$ tzbaa is a good candidate for enhanced emissive properties tunable, in principle, by coordination to different metals or environments.

Here, we report on the synthesis, the crystal structure and the luminescence properties of the first examples of 3D-MOFs, $\left[\mathrm{Zn}(1,3 \text {-tzbaa) }]_{n}\right.$ (1) and $[\mathrm{Zn}(1,4 \text {-tzbaa })]_{n}$ (2), with the new multidentate derivative anionic tzbaa ${ }^{2-}$ ligands, demonstrating the potential of these new linkers to construct novel MOFs. To the best of our knowledge, these are the first examples of MOFs with these derivative ligands, investigated here for the first time. There is only one biological study on

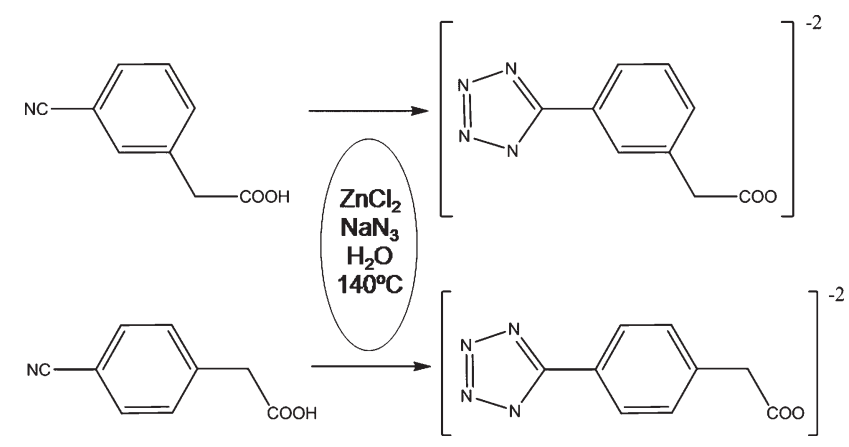

Scheme 1 Spacers obtained in situ by hydrothermal routes. 
$1,4-\mathrm{H}_{2}$ tzbaa, wherein it was used as an inhibitor for the Syk C-terminal $\mathrm{SH} 2$ domain in the biomedical area. ${ }^{8}$

\section{Experimental}

General procedures: unless stated otherwise, all reactions were conducted under hydrothermal conditions, with the reagents purchased commercially and used without further purification.

\subsection{Preparation of complexes}

Preparation of $[\mathrm{Zn}(1,3-\mathrm{tzbaa})]_{\boldsymbol{n}}$ (1). A mixture of $\mathrm{ZnCl}_{2}$ (0.136 g, $1 \mathrm{mmol}), 3$-cyanophenyl acetic acid (0.161 g, $1 \mathrm{mmol})$, sodium azide $(0.195 \mathrm{mg}, 3 \mathrm{mmol})$ and distilled water $(10 \mathrm{~mL})$ was sealed in a Teflon-lined acid digestion autoclave and heated at $160{ }^{\circ} \mathrm{C}$ under autogenous pressure. After $12 \mathrm{~h}$ of heating, the reaction vessel was slowly cooled to room temperature during a period of about $3 \mathrm{~h}$. Yellow crystals of the compound under study were obtained. Yield: $65 \%$, based on $\mathrm{Zn}$. Anal. calcd $\mathrm{C}_{9} \mathrm{H}_{6} \mathrm{~N}_{4} \mathrm{O}_{2} \mathrm{Zn}$ : C 40.37, $\mathrm{H} 2.24$, N 20.93. Found: C 40.78, H 2.81, N 21.29. IR/ $\mathrm{cm}^{-1}: 3421$ (s), 2921 (m), 2850 (w), 1536 (s), 1385 (s), 1209 (m), 1077 (m), $813(\mathrm{~m}), 773(\mathrm{~m}), 742(\mathrm{~s}), 684(\mathrm{~s})$.

Preparation of $[\mathrm{Zn}(1,4-t z b a a)]_{n}$ (2). A mixture of $\mathrm{ZnCl}_{2}$ (0.136 g, $1 \mathrm{mmol})$, 4-cyanophenyl acetic acid $(0.161 \mathrm{~g}$, $1 \mathrm{mmol})$, sodium azide $(0.195 \mathrm{mg}, 3 \mathrm{mmol})$ and distilled water $(10 \mathrm{~mL})$ was sealed in a Teflon-lined acid digestion autoclave and heated at $160{ }^{\circ} \mathrm{C}$ under autogenous pressure. After $12 \mathrm{~h}$ of heating, the reaction vessel was slowly cooled to room temperature during a period of about $3 \mathrm{~h}$. Colourless crystals of the compound under study were obtained. Yield: $39 \%$, based on $\mathrm{Zn}$. Anal. calcd $\mathrm{C}_{9} \mathrm{H}_{6} \mathrm{~N}_{4} \mathrm{O}_{2} \mathrm{Zn}$ : C 40.37, H 2.24, N 20.93. Found: C 40.49, H 2.92, N 21.11. IR/cm ${ }^{-1}: 3440(\mathrm{~m})$, 2957 (w), 2910 (w), 1541 (s), 1382 (s), 1212 (m), 1018 (m), $832(\mathrm{~m}), 743(\mathrm{~m}), 710(\mathrm{~m})$.

\subsection{Physical measurements}

Elemental analyses were carried out at the "Centro de Instrumentación Científica" (University of Granada) on a Fisons-Carlo Erba analyser model EA 1108. IR spectra of the powdered samples were recorded with a Thermo Nicolet IR200 FTIR using KBr pellets.

\subsection{Single-crystal structure determination}

Suitable crystals of 1 and 2 were mounted on a glass fibre and used for data collection on an Agilent SuperNova diffractometer equipped with a CCD area detector using microfocused monochromatic Mo K $\alpha$ radiation $(\lambda=0.71073 \AA)$ by applying the $\omega$-scan method. Lorentz-polarization and empirical absorption corrections were applied. The structures were solved by direct methods and refined with full-matrix leastsquares calculations on $F^{2}$ using the program SHELXS97. ${ }^{9}$ Anisotropic temperature factors were assigned to all atoms except for hydrogen atoms, which are riding on their parent atoms with an isotropic temperature factor arbitrarily chosen
Table 1 Crystallographic data and structural refinement details

\begin{tabular}{|c|c|c|}
\hline Compound & 1 & 2 \\
\hline Formula & $\mathrm{C}_{9} \mathrm{H}_{6} \mathrm{~N}_{4} \mathrm{O}_{2} \mathrm{Zn}$ & $\mathrm{C}_{9} \mathrm{H}_{6} \mathrm{~N}_{4} \mathrm{O}_{2} \mathrm{Zn}$ \\
\hline$M_{\mathrm{r}}$ & 267.55 & 267.55 \\
\hline Crystal system & Orthorhombic & Orthorhombic \\
\hline Space group (no.) & $\operatorname{Pna2}_{1}$ & $\operatorname{Pca}_{1}$ \\
\hline$a(\AA)$ & $10.4858(3)$ & $18.5081(5)$ \\
\hline$b(\AA)$ & $18.8309(6)$ & $4.8230(1)$ \\
\hline$c(\AA)$ & $4.8130(2)$ & $10.9635(4)$ \\
\hline$V\left(\AA^{3}\right)$ & $950.36(6)$ & $978.65(5)$ \\
\hline$Z$ & 4 & 4 \\
\hline$D_{\mathrm{c}}\left(\mathrm{g} \mathrm{cm}^{-1}\right)$ & 1.87 & 1.816 \\
\hline$\mu(\operatorname{MoK} \alpha)\left(\mathrm{mm}^{-1}\right)$ & 2.572 & 2.498 \\
\hline$T(\mathrm{~K})$ & 293 & 293 \\
\hline Observed reflections & $2031(1835)$ & $1955(1510)$ \\
\hline$R_{\text {int }}$ & 0.0303 & 0.0429 \\
\hline Parameters & 145 & 145 \\
\hline GOF & 1.08 & 1.049 \\
\hline$R_{1}^{a}$ for $I>0$ (and for $\left.I>2 \sigma(I)\right)$ & $0.0386(0.0319)$ & $0.0536(0.0347)$ \\
\hline $\mathrm{w} R_{2}{ }^{a}$ for $I>0($ and for $I>2 \sigma(I))$ & $0.0784(0.0731)$ & $0.0677(0.0580)$ \\
\hline Flack parameter & $-0.04(2)$ & $-0.01(2)$ \\
\hline $\begin{array}{l}\text { Largest peak and hole } \\
\left(\mathrm{e} \AA^{-3}\right) \text { of residual density }\end{array}$ & 0.543 and -0.389 & 0.402 and $0 .-348$ \\
\hline${ }^{a} R_{1}=\sum|| F_{\mathrm{o}}|-| F_{\mathrm{c}}|| / \sum\left|F_{\mathrm{o}}\right|, \mathrm{w} R_{2}$ & {$\left[\sum \mathrm{w}\left(F_{\mathrm{o}}{ }^{2}-F_{\mathrm{c}}{ }^{2}\right)^{2} /\right.$} & $\left.w F^{4}\right]^{1 / 2}$ \\
\hline
\end{tabular}

as 1.2 times that of the respective parent. Final $R(F), \mathrm{w} R\left(F^{2}\right)$ and goodness of fit agreement factors as well as details on the data collection and analysis can be found in Table 1 . Selected bond lengths and angles are given in Tables S1 and S2 (ESI $\dagger)$. The CCDC reference numbers for the structures of 1 and 2 are 930950 and 930951.

\subsection{Luminescence measurement}

A Varian Cary-Eclipse fluorescence spectrofluorimeter was used to obtain the fluorescence spectra. The spectrofluorimeter was equipped with a xenon discharge lamp (peak power equivalent to $75 \mathrm{~kW}$ ), Czerny-Turner monochromators, and an R-928 photomultiplier tube which is red sensitive (even $900 \mathrm{~nm}$ ) with manual or automatic voltage control using the Cary Eclipse software for the Windows 95/98/NT system. The photomultiplier detector voltage was $700 \mathrm{~V}$ and the instrument excitation and emission slits were set at 5 and $5 \mathrm{~nm}$, respectively.

\section{Results and discussion}

Hydrothermal reactions of zinc chloride $(1 \mathrm{mmol})$ with 3 -cyanophenyl acetic acid or 4-cyanophenyl acetic acid ( $1 \mathrm{mmol})$ and sodium azide $(3 \mathrm{mmol})$ in water $(10 \mathrm{ml})$ at $160{ }^{\circ} \mathrm{C}$ for $12 \mathrm{~h}$ followed by cooling to room temperature over $3 \mathrm{~h}$ yielded prismatic yellow and colourless crystals of 1 (in $65 \%$ yield) and 2 (in $39 \%$ yield), respectively.

\subsection{Description of the structures}

The crystal structures were determined by single crystal X-ray diffraction. Both MOFs crystallize in the orthorhombic system and in the crystal class $m m 2$, although in two different space 
groups (Pna2 ${ }_{1}$ and $\mathrm{PCa}_{1}$ for $\mathbf{1}$ and 2, respectively). Both form three-dimensional networks, originating from tetrahedral $\mathrm{Zn}^{2+}$ connectors coordinated to four (tzbaa) ${ }^{2-}$ linkers. The binding sites of the (tzbaa) $)^{2-}$ ligands are the two oxygens of the carboxylate group and the two nitrogen atoms (N1 and N4) of the tetrazole ring. (1,3-tzbaa) $)^{2-}$ and $(1,4 \text {-tzbaa })^{2-}$ are structural isomers, therefore the coordination polymers are different. This depends on the distance between the carboxylic and the tetrazole groups in the two ligands, on their mutual orientation and on their conformations. In (1,3-tzbaa $)^{2-}$, the tetrazole and the carboxylic groups are inclined with respect to the phenyl ring by $c a .44^{\circ}$ and $67^{\circ}$, respectively, whereas in $(1,4 \text {-tzbaa })^{2-}$ the planes are less inclined $\left(32^{\circ}\right.$ and $60^{\circ}$, respectively). Details of the principal bonding distances are given in the caption to Fig. 1.

For 2, the $\mathrm{Zn} 1$ atom has a $\mathrm{ZnN}_{2} \mathrm{O}_{2}$ environment in which it is coordinated to two oxygen atoms pertaining to the carboxylate group and two nitrogen atoms from the tetrazolate ring. The network of 2 is characterized by large 6 -member rings made of 3 linkers and 3 connectors, producing apparent channels (however, these are not sufficiently large to host extra-framework molecules). These channels are parallel to $b$ and are therefore perpendicular to the $2_{1}$ helix (Fig. 2, bottom). The rings are formed by two long edges and one short edge. The long edges interconnect one $\mathrm{Zn}$ atom coordinated to the carboxylate group with another $\mathrm{Zn}$ coordinated to the tetrazole group. The short edges interconnect two $\mathrm{Zn}$ atoms linked to $\mathrm{O} 1$ and $\mathrm{O} 2$ or two $\mathrm{Zn}$ atoms linked to $\mathrm{N} 1$ and $\mathrm{N} 4$. This network has the topological type of lonsdaleite (the so-called hexagonal diamond).

The $\mathrm{Zn} 1$ atom in 1 has a tetrahedral $\mathrm{ZnN}_{2} \mathrm{O}_{2}$ geometry in which two positions are occupied by two oxygen atoms pertaining to carboxylate groups of different $(1,4 \text {-tzbaa })^{2-}$ ligands; the other positions are occupied by nitrogen atoms from tetrazolate rings. In this case, the structure of $\mathbf{1}$ is more complex (Fig. 2, top), having three different types of cycles: one 8-member ring ( 4 connectors +4 linkers); three 6-member rings ( 4 connectors +2 linkers); and two
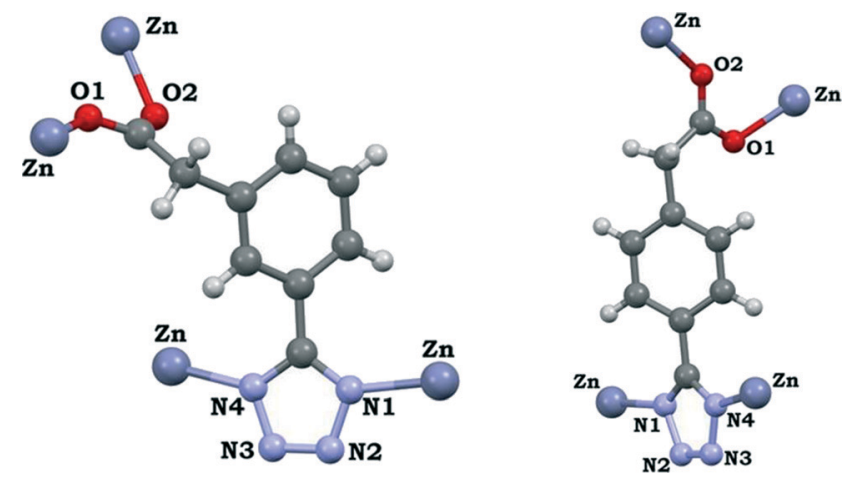

Fig. 1 A view of the coordination mode of the ligands (1,3-tzbaa) ${ }^{2-}$ and (1,4-tzbaa) ${ }^{2-}$ for 1 (left) and 2 (right), respectively. Selected bond distances for 1 and 2 respectively: Zn-N1 2.001(3), 1.991(5); Zn-N4 1.965(3), 1.973(6); O(1)-Zn(1) 1.972(3), 1.965(2); O(2)-Zn(1) 1.962(3), $1.976(2) ; \mathrm{N}(1)-\mathrm{N}(2)$ 1.361(4)，1.379(6); $\mathrm{N}(2)-\mathrm{N}(3)$ 1.287(4)，1.285(5); $\mathrm{N}(3)-\mathrm{N}(4) 1.348(4), 1.352(6)$.
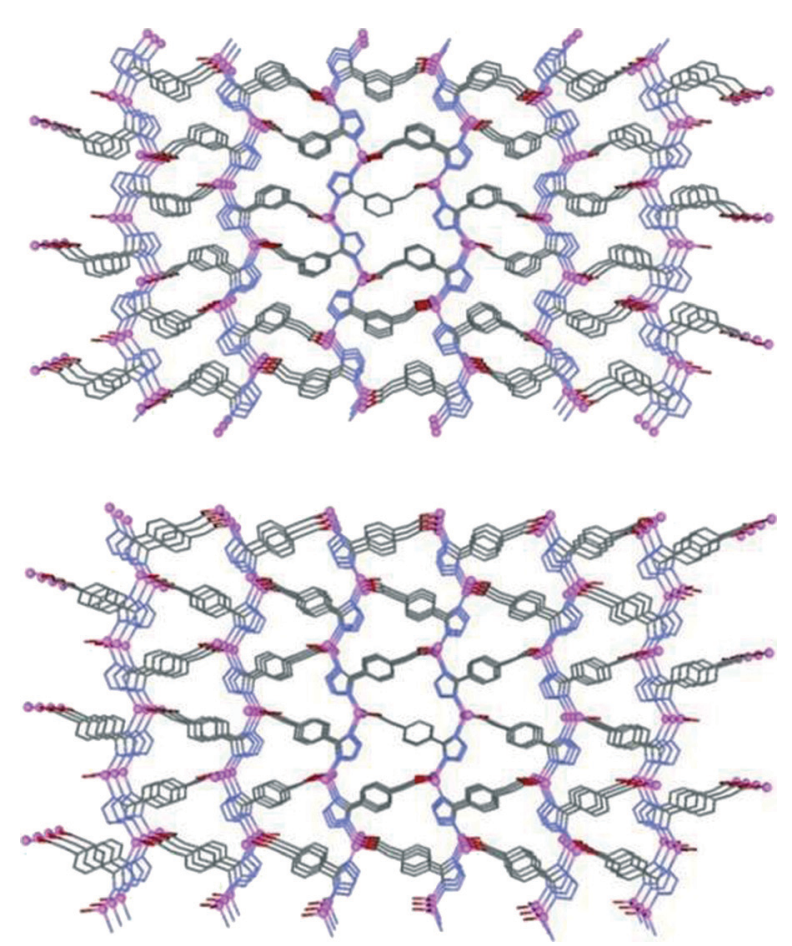

Fig. 2 Packings of 1 (top) and 2 (bottom) along $c$ and $b$ axes, respectively.

4-member rings ( 2 connectors +2 linkers). The 4 - and 8-member rings form apparent channels along the helical axis $c$, visible in Fig. 2 (top), whereas the 6-member ones form channels perpendicular to the plane of the plot and parallel to $a$. The network has the topology of $\mathrm{SrAl}_{2}$, which is quite frequent for MOFs.

\subsection{Luminescence studies}

The emission spectra of 1 and 2 in the solid state at room temperature are shown in Fig. 3. Broad intense emission bands are observed, centred at about $\lambda=449$ and $479 \mathrm{~nm}$, respectively, upon excitation at $\lambda=350 \mathrm{~nm}$. The emission in complexes 1 and 2 is assigned to intraligand $\pi \rightarrow \pi^{*}$ transitions. The emission spectra of 1 and 2, as well as those of free 1,3-tzbaa ${ }^{2-}$ and 1,4-tzbaa ${ }^{2-}$ ligands, were also calculated computationally. All theoretical calculations were performed

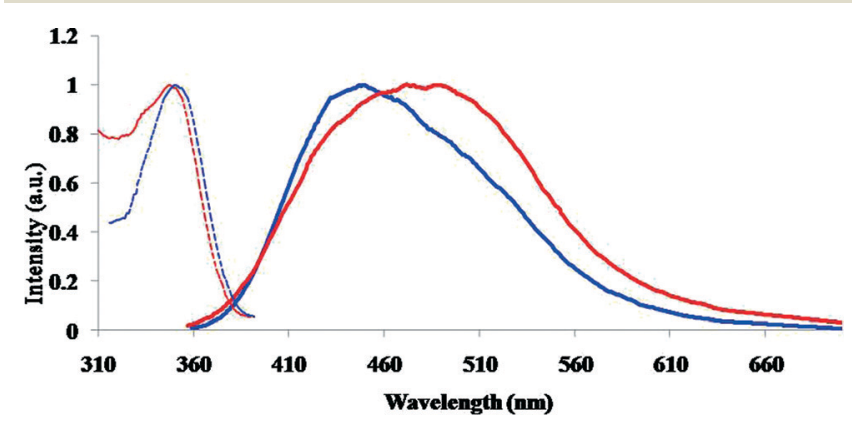

Fig. 3 The emission spectra of 1 (blue) and 2 (red) after excitation at $350 \mathrm{~nm}$ in the solid state at room temperature. 

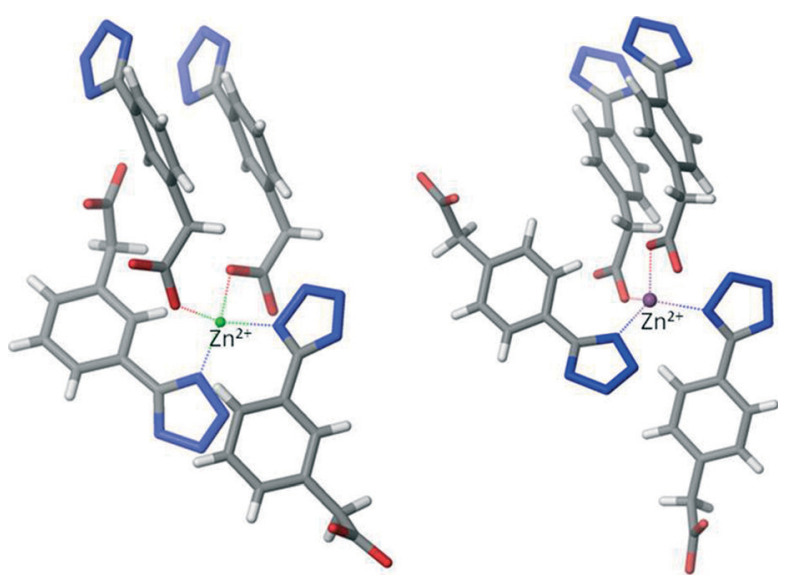

Fig. 4 Models 1 and 2 generated from the crystal structures of 1 and 2 , respectively.

using the Gaussian 09 package. ${ }^{10}$ The atomic coordinates of 1 and $\mathbf{2}$ were obtained from their corresponding crystal structures, with both systems reduced to their minimum possible size (models 1 and 2 hereafter), i.e., the first coordination sphere of a $\mathrm{Zn}^{2+}$ cation (see Fig. 4). The energy calculation and geometry optimization of the first six vertical excited singlet and triplet states were carried out using time-dependent density functional theory (TD-DFT), the B3LYP functional ${ }^{11}$ and the $6-31 \mathrm{G}+(\mathrm{d}, \mathrm{p})$ basis set for all atoms. The molecular orbitals were visualized using gMolden ${ }^{12}$ and the emission spectra data were processed using Microsoft Excel (2007).

Theoretical TD-DFT studies revealed that the absorption and emission spectra of compounds 1 and 2 (Table 1) are related to the intrinsic electronic properties of ligands 1,3-tzbaa ${ }^{2-}$ and 1,4-tzbaa ${ }^{2-}$ (Table S3 and Fig. S6†), respectively, which are generated in situ in the reaction path of compounds 1 and 2.

Interestingly, theoretical TD-DFT calculations estimated a $30 \mathrm{~nm}$ shift between the emission maxima of models 1 and 2 (474 $\mathrm{nm}$ vs. $504 \mathrm{~nm}$ ), respectively, which agrees with the $30 \mathrm{~nm}$ shift observed experimentally (449 $\mathrm{nm} v s .479 \mathrm{~nm}$ ) (Fig. 5). Model 1 shows a LUMO $\rightarrow$ HOMO transition at $474 \mathrm{~nm}$ (Table 2 and Fig. 5), $25 \mathrm{~nm}$ red shifted as compared to the experimental results $(449 \mathrm{~nm})$. Model 2 shows a LUMO+1 $\rightarrow$ HOMO and a LUMO $\rightarrow$ HOMO relaxation at 417 and $504 \mathrm{~nm}$, respectively, slightly red shifted as compared to the experimental results $(479 \mathrm{~nm})$.

As observed from the shape of the orbitals depicted in Fig. 6, the emission spectra observed experimentally are related to $\pi^{*} \rightarrow \pi$ transitions between the aromatic ring and the carboxylic group of the ligands (Fig. 6) present in the described MOFs.

The similarity of the emission spectra of 1 and 2 is in agreement with the explanation, which indicates that ligandcentered $\pi-\pi^{*}$ excitation is responsible for the emission. In contrast with $\mathrm{Zn}$ complexes of 5-aliphatic tetrazolates that usually show emission in the range of $390-420 \mathrm{~nm},{ }^{13}$ energetic emission in $\mathbf{1}$ and $\mathbf{2}$ possibly comes from the conjugation of the tetrazolate and phenyl-carboxylate groups. The decay curves were fitted to the mono-exponential function

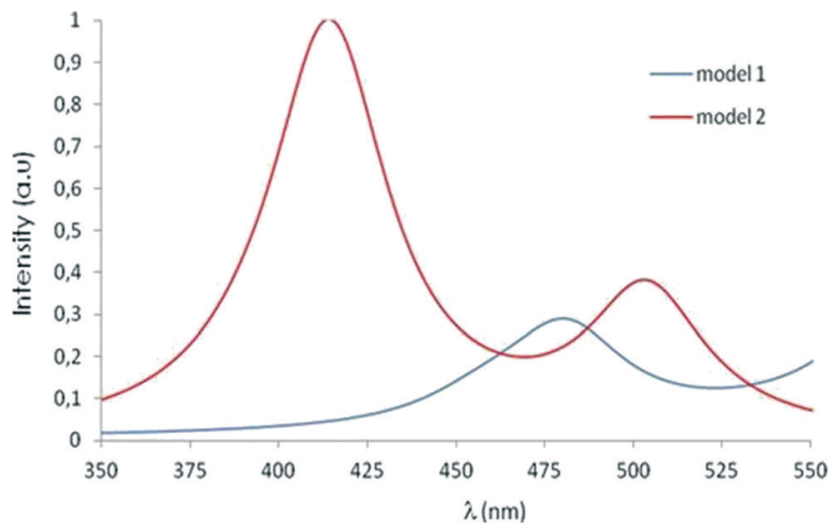

Fig. 5 Calculated emission spectra of models 1 and 2.

Table 2 Experimental and calculated emission maxima and the corresponding transitions for models 1 and 2

\begin{tabular}{llll} 
Compound & Exp. emis. (nm) & Calc. emis. (nm) & Calc. transitions \\
\hline 1 & 449 & 474 & HOMO $\leftarrow$ LUMO \\
2 & 479 & 417 & HOMO $\leftarrow$ LUMO+1 \\
& & 504 & HOMO $\leftarrow$ LUMO
\end{tabular}

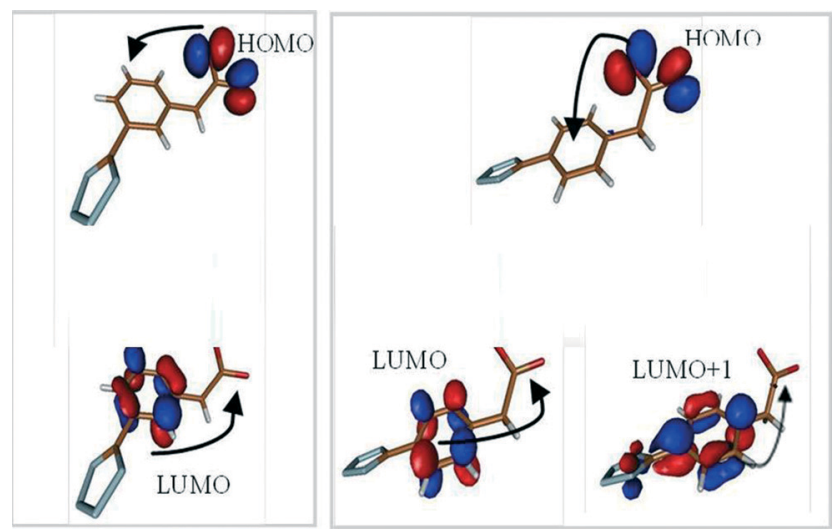

Fig. 6 Representation of the molecular orbitals involved in the absorption (top) and emission (bottom) spectra of compounds 1 and 2.

$I=I_{0}+A_{1} \exp (-t / \tau)$, where $I$ and $I_{0}$ are the luminescence intensities at time $t$ and 0 and $\tau$ is defined as the luminescence lifetime. For this function, the best fit of the experimental luminescence intensities to the above equation led to the lifetimes of $0.084 \mathrm{~ms}$ and $0.098 \mathrm{~ms}$ for 1 and 2, respectively.

\section{Conclusions}

We have succeeded in synthesising the first metal-organic frameworks with the 1,3-tetrazolatephenyl-acetic and 1,4tetrazolatephenyl-acetic spacer ligands. These compounds show fascinating structures with intense blue-green photoluminescence emission at room temperature in the solid state. To the best of our knowledge, this is the first time that coordination compounds have been synthesized with these new multidentate ligands. 


\section{Acknowledgements}

This work was supported by the Junta de Andalucía (FQM-1484) (A. J. Calahorro was supported by a postdoctoral grant) and by the Swiss National Science Foundation (project no. 141271). SGI/IZO-SGIker UPV/EHU is gratefully acknowledged for the generous allocation of computational resources.

\section{References}

1 (a) H. Xu, X. Rao, J. Gao, J. Yu, Z. Wang, Z. Dou, Y. Cui, Y. Yang, B. Chen and G. Qian, Chem. Commun., 2012, 48, 7377-7379; (b) M. M. Wanderley, C. Wang, C.-D. Wu and W. Lin, J. Am. Chem. Soc., 2012, 134, 9050-9053; (c) P. Kar, R. Haldar, C. J. Gomez-Garcia and A. Ghosh, Inorg. Chem., 2012, 51, 4265-4273; (d) S. T. Hyde, O. Delgado-Friedrichs, S. J. Ramsden and V. Robins, Solid State, 2006, 8, 740-752.

2 (a) F. A. Almeida Paz and J. Klinowski, Chem. Commun., 2003, 1484; (b) L. G. Westin, M. Kritikos and A. Caneschi, Chem. Commun., 2003, 1012; (c) B.-Q. Ma, D.-S. Zhang, S. Gao, T.-Z. Jin, C.-H. Yan and G.-X. Xu, Angew. Chem., Int. Ed., 2000, 39, 3644; (d) J. Seo, C. Bonneau, R. Matsuda, M. Takata and S. Kitagawa, J. Am. Chem. Soc., 2011, 133, 9005-9013.

3 (a) R. Shunmugam and G. N. Tew, J. Am. Chem. Soc., 2005, 127, 13567; (b) M. Ji, X. Lan, Z. Han, C. Hao and J. Qiu, Inorg. Chem., 2012, 51, 12389-12394; (c) Y. Yang, P. Du, J.-F. Ma, W.-Q. Kan, B. Liu and J. Yang, Cryst. Growth Des., 2011, 11, 5540-5553; (d) F. Tong, Z.-G. Sun, K. Chen, Y.-Y. Zhu, W.-N. Wang, C.-Q. Jiao, C.-L. Wang and C. Li, Dalton Trans., 2011, 40, 5059-5065.

4 (a) Q.-G. Zhai, Q. Lin, T. Wu, L. Wang, S.-T. Zheng, X. Bu and P. Feng, Chem. Mater., 2012, 24, 2624-2626; (b) W. Morris, N. He, K. G. Ray, P. Klonowski, H. Furukawa, I. N. Daniels, Y. A. Houndonougbo, M. Asta, O. M. Yaghi and B. B. Laird, J. Phys. Chem. C, 2012, 116, 24084-24090; (c) P.-Q. Liao, D.-D. Zhou, A.-X. Zhu, L. Jiang, R.-B. Lin, J.-P. Zhang and X.-M. Chen, J. Am. Chem. Soc., 2012, 134, 17380-17383; (d) P. Cui, Y.-G. Ma, H.-H. Li, B. Zhao, J.-R. Li, P. Cheng, P. B. Balbuena and H.-C. Zhou, J. Am. Chem. Soc., 2012, 134, 18892-18895.

5 (a) C. L. Cahill, D. T. de Lill and M. Frisch, CrystEngComm, 2007, 9, 15; (b) J. C. G. Bünzli and C. Piguet, Chem. Soc. Rev., 2005, 34, 1048; (c) A. Y. Robin and K. M. Fromm,
Coord. Chem. Rev., 2006, 250, 2127; (d) G. Lu and J. T. Hupp, J. Am. Chem. Soc., 2010, 132, 7832-7833; (e) B. Gole, A. K. Bar and P. S. Mukherjee, Chem. Commun., 2011, 47, 12137-12139.

6 (a) Z. P. Demko and K. B. Sharpless, J. Org. Chem., 2001, 66, 7945; (b) A. Rodríguez-Diéguez, R. Kivekäs and E. Colacio, Chem. Commun., 2005, 5228.

7 (a) A. Rodríguez-Diéguez, J. Cano, R. Kivekäs, A. Debdoubi and E. Colacio, Inorg. Chem., 2007, 46, 2503; A. Rodríguez-Diéguez, J. M. Seco and E. Colacio, Eur. J. Inorg. Chem., 2012, 203; (b) A. Rodríguez-Diéguez, A. Salinas-Castillo, A. Sironi, J. M. Seco and E. Colacio, CrystEngComm, 2010, 12, 1876.

8 T. Niimi, M. Orita, M. Okazawa-Igarashi, H. Sakashita, K. Kikuchi, E. Ball, A. Ichikawa, Y. Yamagiwa, S. Sakamoto, A. Tanaka, S. Tsukamoto and S. Fujita, J. Med. Chem., 2001, 44, 4737-4740.

9 G. M. Sheldrick, SHELX97, program for crystal structure refinement, University of Göttingen, Göttingen, Germany, 1997.

10 M. J. Frisch, G. W. Trucks, H. B. Schlegel, G. E. Scuseria, M. A. Robb, J. R. Cheeseman, G. Scalmani, V. Barone, B. Mennucci, G. A. Petersson, H. Nakatsuji, M. Caricato, X. Li, H. P. Hratchian, A. F. Izmaylov, J. Bloino, G. Zheng, J. L. Sonnenberg, M. Hada, M. Ehara, K. Toyota, R. Fukuda, J. Hasegawa, M. Ishida, T. Nakajima, Y. Honda, O. Kitao, H. Nakai, T. Vreven, J. A. Montgomery Jr., J. E. Peralta, F. Ogliaro, M. Bearpark, J. J. Heyd, E. Brothers, K. N. Kudin, V. N. Staroverov, R. Kobayashi, J. Normand, K. Raghavachari, A. Rendell, J. C. Burant, S. S. Iyengar, J. Tomasi, M. Cossi, N. Rega, J. M. Millam, M. Klene, J. E. Knox, J. B. Cross, V. Bakken, C. Adamo, J. Jaramillo, R. Gomperts, R. E. Stratmann, O. Yazyev, A. J. Austin, R. Cammi, C. Pomelli, J. W. Ochterski, R. L. Martin, K. Morokuma, V. G. Zakrzewski, G. A. Voth, P. Salvador, J. J. Dannenberg, S. Dapprich, A. D. Daniels, O. Farkas, J. B. Foresman, J. V. Ortiz, J. Cioslowski and D. J. Fox, Gaussian 09, revision A.02, Gaussian, Inc., Wallingford, CT, 2009.

11 (a) C. Adamo and V. Barone, J. Chem. Phys., 1999, 110, 6158-6169; (b) C. Adamo and V. Barone, Chem. Phys. Lett., 1997, 274, 242-250; (c) C. Adamo and V. Barone, J. Chem. Phys., 1998, 108, 664-675.

12 G. Schaftenaar and J. H. Noordik, J. Comput.-Aided Mol. Des., 2000, 14, 123-134.

13 X.-S. Wang, Y.-Z. Tang, X.-F. Huang, Z.-R. Qu, C.-M. Che, P. W. H. Chan and R.-G. Xiong, Inorg. Chem., 2005, 44, 5278. 